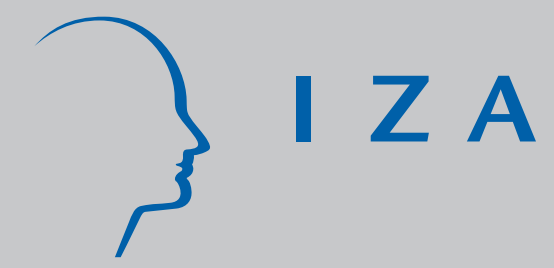

IZA DP No. 364

Examining the Impact of Macro-Economic Conditions on Income Inequality

Markus J äntti

Stephen P. J enkins

September 2001 


\title{
Examining the Impact of \\ Macro-Economic Conditions on \\ Income Inequality
}

\author{
Markus Jäntti \\ Department of Economics, University of Tampere, Finland \\ Stephen P. Jenkins \\ Institute for Social and Economic Research, University of Essex \\ and IZA, Bonn \\ Discussion Paper No. 364 \\ September 2001 \\ IZA \\ P.O. Box 7240 \\ D-53072 Bonn \\ Germany \\ Tel.: +49-228-3894-0 \\ Fax: +49-228-3894-210 \\ Email: iza@iza.org
}

This Discussion Paper is issued within the framework of IZA's research area The Welfare State and Labor Markets. Any opinions expressed here are those of the author(s) and not those of the institute. Research disseminated by IZA may include views on policy, but the institute itself takes no institutional policy positions.

The hstitute for the Study of Labor (IZA) in Bonn is a local and virtual international research center and a place of communication between science, politics and business. IZA is an independent, nonprofit limited liability company (Gesellschaft mit beschränkter Haftung) supported by the Deutsche Post AG. The center is associated with the University of Bonn and offers a stimulating research environment through its research networks, research support, and visitors and doctoral programs. IZA engages in (i) original and internationally competitive research in all fields of labor economics, (ii) development of policy concepts, and (iii) dissemination of research results and concepts to the interested public. The current research program deals with (1) mobility and flexibility of labor markets, (2) internationalization of labor markets and European integration, (3) the welfare state and labor markets, (4) labor markets in transition, (5) the future of work, (6) project evaluation and (7) general labor economics.

IZA Discussion Papers often represent preliminary work and are circulated to encourage discussion. Citation of such a paper should account for its provisional character. 
IZA Discussion Paper No. 364

September 2001

\section{ABSTRACT}

\section{Examining the Impact of Macro-Economic Conditions on Income Inequality}

This paper proposes a new approach for analyzing the relationship between macroeconomic factors and the income distribution. The conventional method of analysis is regression of summary inequality indices on variables such as the unemployment and inflation rates. Building on the lessons from recent advances in time-series econometrics, we suggest instead that one should first fit a parametric functional form to the income distribution for each year, and then model the time series of model parameters in terms of the macroeconomic factors. Inferences about the relationship between the income distribution and macroeconomic factors can be derived from the model estimates. We apply these methods to data from the United Kingdom for 1961-91, and contrast the results with those found using earlier methods.

JEL Classification: C51, D31, E6

Keywords: Income inequality, macro-economic conditions, unemployment, inflation, Singh-Maddala distribution

Stephen P. Jenkins

Institute for Social and Economic Research (ISER)

University of Essex

Colchester, CO4 3SQ

UK

Tel.: +44 (0)1206 873374

Fax: $+44(0) 1206873151$.

Email: stephenj@essex.ac.uk

\footnotetext{
* Jäntti acknowledges support from the Yrjö Jahnsson Foundation and the Academy of Finland. Jenkins acknowledges core funding support to ISER from the Economic and Social Research Council and the University of Essex. He also acknowledges support from the EU TMR Network 'Living standards, inequality and taxation', Contract No. ERBFMRXCT 980248.
} 


\section{Introduction}

The effects of macroeconomic phenomena on the distribution of income are of continuing policy interest. For example, income inequality increased in most OECD countries during the 1980s and 1990s. To what extent can these increases in inequality be attributed to secular rises in unemployment? Is inflation most costly for the poor, as argued by e.g., the former Director of the German Central Bank, Hans Tietmeyer? ${ }^{1}$ In this paper we provide new answers to these questions for the United Kingdom using methods from modern dynamic econometrics and contrast them with the answers revealed by 'first generation' methods.

There is a body of literature starting with Blinder and Esaki (1978) that examines the impact of unemployment and inflation on income inequality. The econometric methods used in these first generation studies involve least squares regressions of income quintile group shares or inequality indices on covariates such as the unemployment rate and inflation rate plus other macroeconomic indicators. Later 'second-generation' research has instead applied methods from dynamic econometrics, testing for unit roots and, typically finding that the series are integrated, modelling the cointegrating relationships. We argue that the first- and second-generation approaches are logically flawed and propose an alternative that is not. We apply these new methods to UK data covering 1961-1991. Our results suggest that the relationship between the income distribution and macroeconomic factors is a complex one, whereas first- and second-generation methods provide a misleadingly over-simplified picture.

\section{Previous methods}

In this section we briefly review how earlier studies have examined of the impact of macro-economic activity on income distribution. There exists a literature about the reverse phenomenon, the impact of income distribution on macro-economic activity (Persson and Tabellini; 1994; Das; 1993), but we do not discuss it in this paper.

The typical study examines a time series of annual data annual data on either the income shares of quantile groups (most often quintile or quartile groups), or some inequality index. The income 
shares and inequality indices are usually estimated in US studies from surveys such as the annual Current Population Survey. The dependent variables are regressed against a number macroeconomic variables, possibly including both contemporaneous and lagged values.

Studies that examine these issues are summarized by Parker (1998-99) and the methods that are used are discussed critically by Parker (2000). Most of the 'first generation' studies, beginning with Blinder and Esaki (1978), have used data for the United States. ${ }^{2}$ There is one previous study using UK data (Nolan; 1988-89), one study using Swedish data (Björklund; 1991), and one using Canadian data (Beach and McWatters; 1990). These studies have typically found that unemployment had a regressive impact and no statistically significant association with inflation. Leslie and $\mathrm{Pu}(1995)$ examined the impact on British wage inequality measured by the 90:10 percentile ratio, of various macroeconomic variables including unemployment and inflation.

Studies that employ modern econometric methods are motivated by the premise that, if the explanatory variables are non-stationary, then the estimators of the regression parameters have nonstandard distributions. Ashworth (1994), Parker (1996), and Mocan (1999), are examples of such 'second-generation' studies. Statistical inference that mistakenly uses standard asymptotic results can and does lead to erroneous conclusions. These authors applied the framework of dynamic econometrics (see e.g. Hendry; 1995) to the analysis of macroeconomic variables and income quantile group shares or inequality indices. Specifically, they examined whether each time series had a unit root and, if this turned out to be the case, they proceeded to model their cointegration relations.

Our paper was motivated by the view that it is often inappropriate even to examine whether inequality indices and income shares have unit roots, because most commonly used indicators of inequality have logical bounds.

Consider, for example, quintile group income shares. Let $S_{i, t}$ be the share of the $i$ th income quintile group in year $t=1, \ldots, T$. We know that $S_{i, t} \in[0,1]$ and that $0 \leq S_{1, t} \leq \cdots \leq S_{5, t} \leq 1$. It follows from the boundedness of the income shares that their variance is finite:

$$
\operatorname{Var}\left(S_{i, t}\right)<\infty, \forall t
$$


Consider the simplest possible case of a variable that is integrated of order $1[I(1)]$, the random walk,

$$
S_{i, t}=S_{i, t-1}+\varepsilon_{i, t}
$$

where $\varepsilon_{i, t} \sim N\left(0, \sigma_{i}^{2}\right)$. This implies, assuming for simplicity of exposition i.i.d. error terms, that

$$
\begin{aligned}
S_{i, t} & =\sum_{\tau=0}^{t} \varepsilon_{i, t} \\
\Rightarrow \quad \operatorname{Var}\left(S_{i, t}\right) & =t \sigma^{2} \\
\Rightarrow \quad \lim _{t \rightarrow \infty} \operatorname{Var}\left(S_{i, t}\right) & \rightarrow \infty .
\end{aligned}
$$

The properties that the shares are bounded (1) and that the variance of the income shares grows without bound as $t$ increases ( 3 ) are mutually contradictory. Variables that are bounded in the unit interval can not have an infinite variance. Standard unit-root tests in the 'second-generation' studies cited above have typically led analysts to accept the unit root hypothesis. However, this leads them to accept a hypothesis that can not, on logical grounds, be true. Most commonly used inequality indices are bounded. Most often they are restricted to lie in the unit interval.

\section{Proposed New Methods}

Our purpose is to examine whether macroeconomic factors affect income inequality. We have argued that, because of the potential non-stationarity of both the regressands and regressors, it is unsatisfactory to estimate the parameters directly by, e.g., linear regressions of the form

$$
I_{t}=X_{t} \beta+\varepsilon_{t}
$$

where $I_{t}$ can be a scalar index or vector of income shares and $X_{t}$ is the vector of covariates whose impact on inequality we are interested in. However, logical restrictions on the regressand (and possibly on some of the regressors) suggest that standard methods for the analysis of integrated processes are not appropriate either.

We therefore choose a route that allows us to use such methods. That is, we study regressands that 
can, at least in principle, take any (positive) values. Our proposed new methods are as follows. We choose a suitable functional form $F\left(y ; \theta_{t}\right)$ for the income distribution and estimate the appropriate parameter vectors $\theta_{t}$. We examine the time series properties of $\left(\theta_{t}^{\prime}, X_{t}^{\prime}\right)$ and proceed to estimate regression equations of the form

$$
\theta_{t}=X_{t} \beta+\varepsilon_{t}
$$

All income distribution statistics can be estimated by the appropriate functionals

$$
I\left[F\left(y ; \hat{\theta}_{t}\right)\right]=I\left[F\left(y ; X_{t} \hat{\beta}\right)\right]
$$

This formulation also allows us to isolate the effect of variations in a particular covariate, such as the unemployment rate, on changes in income inequality. For instance, we can examine how variations in the unemployment rate $u$, keeping all else constant, impact on the Gini coefficient by graphing

$$
G=G_{F}(u \mid \tilde{X} \backslash u ; \hat{\beta}),
$$

where $\tilde{X} \backslash u$ denotes a particular choice of values, typically sample means, for the vector of covariates $X$ other than the unemployment rate. This can be generalized to the examination of the Gini coefficient as a function of e.g. unemployment and inflation, or by looking at some other income distribution statistic, such as the income share of the richest fifth.

We used two different functional forms for the income distribution, namely the Singh-Maddala one (Singh and Maddala; 1976) and the Dagum one (Dagum; 1980). Both these distributions have three parameters, only two of which are required to characterize indices of relative inequality (see below). In Table 1, we show the formulae describing the cumulative distribution functions, moments, Gini coefficients and Lorenz curves for the Singh-Maddala and the Dagum distributions. McDonald (1984) examined the goodness of the fit of several three- and four-parameter distributions and found using grouped income distribution data that the Singh-Maddala distribution was the best performer of all three-parameter distributions and provided a better fit than one four-parameter distribution. Brachman et al. (1996) and Jenkins (1999) demonstrated the good fit of the Singh-Maddala distribution using micro-data from Germany and the UK. Our proposed methods do not of course rely on 
the choice of a specific functional form. The same approach could be taken using forms other than the Singh-Maddala or Dagum distribution if desired. The main requirement is that the functional form fits well (and we show below that the ones we use do).

\section{[Table 1 about here.]}

To give some idea of how inequality is related to the parameters we plot the Gini coefficient as a function of the two Singh-Maddala parameters $a$ and $q$ : see Figure 1. The range of values for the parameters is equal to that observed in the UK during the sample period (see below). The Gini coefficient decreases in both parameters, as suggested by the negatively sloped contours that show decreasing levels of the Gini coefficient as we move from the southwest corner of Figure 1 to the northeast corner, with the Gini coefficient declining from a high value of 0.38 to 0.22 .

In order to show in greater detail how inequality depends on the two parameters, we have in Figure 2 plotted the income share contours of the poorest and richest fifth in the $a-q$-plane. The contours of the share of the poorest fifth increase on moving along the main diagonal from lower values of $a$ and $q$ to higher values. The income share of this lowest quintile group ranges from a low of 6 percent in the southwest to a high of 10.5 percent in the northeast. The income share of the richest fifth, in turn, decreases on moving to the northeast, ranging from a high of 48 percent to a low of 32 percent in the very northeast corner. We shall use a similar device below to show how inequality varies with covariate values. That is, rather than show, say, the Gini coefficient $G=G[F(a, q)]$ as a function of the parameters, we substitute the estimated parameter vector with appropriately chosen covariate values to graph inequality as a function of the range of variation of a (pair of) covariate(s) as exemplified in equation (7).

[Figure 1 about here.]

[Figure 2 about here.]

In estimating the distribution functions for the UK, we found similar results for both SinghMaddala and Dagum distributions and therefore concentrate on the Singh-Maddala one in what follows. Note that the Gini coefficient and Lorenz curve depend only on the parameters $a$ and $q .{ }^{3}$ 
As we are primarily interested in relative inequality we will drop $b$ from further analysis. Let $\theta_{t}=$ $\left(a_{t}, q_{t}\right)^{\prime}$ be the vector of parameters of interest. We suppose that their evolution may be summarised by the following model:

$$
\theta_{t}=X_{t}^{*} \beta^{*}+\varepsilon_{t}
$$

where $X_{t}^{*}=X_{t} \otimes I_{2}$ is the matrix of regressors, $\varepsilon=\left(\varepsilon_{1}, \varepsilon_{2}\right)^{\prime}$ is i.i.d. normal with zero mean and covariance matrix $\Sigma$. If all the variables that are involved are stationary, $\beta^{*}$ can be estimated using GLS.

We do not observe $\theta_{t}$ however. Instead we have access to its sample (ML) estimate, $\hat{\theta}_{t}=\theta_{t}+\eta_{t}$, where we assume $\eta_{t} \sim N\left(0, \Omega_{t}\right)$. That is, the fact that the income distribution parameters are sample estimates of the population parameters renders the variance of the estimating equation larger than that in equation 8 and heteroskedastic. Instead of equation 8 we estimate

$$
\hat{\theta}_{t}=X_{t}^{*} \beta^{*}+\varepsilon_{t}-\eta_{t}
$$

The variance of the error term is $\operatorname{Var}\left(\varepsilon_{t}-\eta_{t}\right)=\Sigma+\Omega_{t}$. The variance-covariance matrix of the joint residuals is then

$$
\Gamma=\Sigma \otimes I_{T}+\Omega
$$

where

$$
\Omega=\left[\begin{array}{cccc}
\Omega_{1} & 0 & \ldots & 0 \\
0 & \Omega_{2} & \ldots & 0 \\
\vdots & \vdots & \ddots & \vdots \\
0 & \ldots & \ldots & \Omega_{T}
\end{array}\right]
$$

is the block-diagonal matrix with the estimated variance-covariance matrix of the Singh-Maddala parameters on the main diagonal. This suggests that a Feasible Generalized Least Squares (FGLS) 
estimate can be obtained by solving the problem

$$
\begin{aligned}
& \min _{\beta}\left(\hat{\theta}_{t}-X_{t}^{*} \beta_{*}\right)^{\prime} \Gamma^{-1}\left(\hat{\theta}_{t}-X_{t}^{*} \beta_{*}\right) \\
\Leftrightarrow & \min _{\beta}\left(\hat{\theta}_{t}-X_{t}^{*} \beta_{*}\right)^{\prime} U^{\prime} U\left(\hat{\theta}_{t}-X_{t}^{*} \beta_{*}\right) \\
\Leftrightarrow & \min _{\beta}\left(U \hat{\theta}_{t}-U X_{t}^{*} \beta_{*}\right)^{\prime}\left(U \hat{\theta}_{t}-U X_{t}^{*} \beta_{*}\right)
\end{aligned}
$$

where $U$ is given by a Cholesky decomposition of the inverse of the full covariance matrix $U^{\prime} U=$ $\Gamma^{-1}$. This estimator becomes feasible when the true, unknown value of $\Gamma$ is replaced with its estimate, constructed by adding that variance-covariance matrix of the maximum likelihood estimates of $\theta$ to an estimate of $\Sigma$ based on OLS residuals from equation 8 .

\section{Data}

The income distribution data used to estimate our distribution function parameters come from the UK Family Expenditure Survey subfiles derived by Goodman and Webb (1994). The microdata files cover each year between 1961 and 1991 inclusive and contain consistently defined income variables (by contrast with official FES files). The number of households in the survey ranges from a low of 1,500 in 1964 and around 3,000 in 1961-66 to around 7000 in 1967 and thereafter (covering some 15,000 persons).

The measure of income, 'equivalent current net household income', is a standard one. Net household income refers to post-tax post-transfer income. The data are adjusted for differences in household size and composition using the semi-official 'McClements Before Housing Costs' equivalence scale. Each person's living standard is measured by the income of the household to which he or she belongs. The definition of income is exactly the same as used in the UK's official income statistics.

We dropped negative income values from the analysis. This is because the Singh-Maddala distribution is defined for $y \geq 0$, whereas the Dagum is defined for $y>0$. We estimated the Singh-Maddala model twice, first with data including zero incomes, and second excluding them. The estimated Singh-Maddala parameters were very similar. We conclude that the treatment of zeros does not affect the results. ${ }^{4}$ 
The data summarizing macroeconomic phenomena are those reported in the appendices to Goodman and Webb (1994), and were taken from standard sources. Economic growth is measured by the annual percentage change in real GDP. The inflation rate is measured using the GDP deflator and the interest rate by the London Inter-Bank Offered Rate. The measure of unemployment is the overall rate of unemployment. Separate series for men and women are desirable because men's and women's unemployment arguably have different effects on the distribution of income. However, no consistently-defined series for the whole period 1961-91 were available for each sex separately (related to a change in 1971 in the definition of unemployment).

[Figure 3 about here.]

The values of the macroeconomic variables we use are displayed in Figure 3. The various unemployment series, shown in Figure 3(a), track each other fairly closely, with one major exception. Prior to 1971 women were more likely than men to be unemployed, but from 1971 onwards this pattern was reversed. Unfortunately this change coincides with a change in the definition of unemployment. The unemployment series appear to display non-stationary behavior, with increasingly large fluctuations. The series for real GDP growth, inflation and the real interest rate, shown in Figure 3(b) also exhibit fairly stable patterns in the 1960s and after 1985, while the period between the two oil shocks exhibits large fluctuations.

[Figure 4 about here.]

Figure 4 summarizes UK income distribution trends over the period. Shown are the Gini coefficient and one-half of the squared coefficient of variation $\left(C V^{2} / 2\right)$ (in Figure 4(a)) and the income quintile group shares (in Figure 4(b)), in each case calculated non-parametrically from the FES microdata. The Gini coefficient and the $C V^{2} / 2$ move quite similarly, although the $C V^{2} / 2$ appears to display greater fluctuation. We focus on the Gini coefficient in what follows.

Income inequality had little apparent trend during the 1960s, possibly declined in the early 1970s, and increased every year after the late-1970s. Looking at the quintile group shares, it appears that all of the increase was due to increases in the income share of the richest fifth, while the poorest fifth apparently bore the greatest loss. This increase at the top is consistent with the larger increase in the 
$C V^{2} / 2$ than in the Gini: the Gini is most sensitive to income transfers round the middle (mode) of the distribution, whereas $C V^{2} / 2$ is most sensitive to income transfers at the top of the distribution.

[Figure 5 about here.]

Figure 5 shows how well the statistics implied by the estimated functional forms track the statistics estimated directly from the micro-data. The Singh-Maddala Gini tracks the non-parametric estimate closely - the correlation coefficient between the two series is 0.98 . The largest percentage difference between the two series is 1.1 percent and occurs in 1964 and 1967, which were the years with the smallest sample size and when only the first two quarters of data were available (see Goodman and Webb; 1994, p. 7).

\section{Results: 'First generation' and new methods compared}

\section{III.1 Regressions of income shares on macro variables}

[Table 2 about here.]

Estimates from quintile group share regressions (the 'first generation' method) are displayed in Table 2. The specification is standard, and follows Blinder and Esaki (1978). We included as regressors the overall unemployment rate, the inflation rate, the real GDP growth rate and the real interest rate. Only the first four quintile groups were included in the estimating equations: for the fifth group the regression coefficients and their associated standard errors were estimated using the adding up constraints. ${ }^{5}$ The coefficients for unemployment and for inflation are jointly statistically significant, but the estimated coefficients imply quite small effects. The coefficients for the real interest rate and the real GDP growth rate are also statistically significant at the 5 percent level.

There is a surprising pattern across the quintile groups for the estimated coefficients on the unemployment rate. Higher unemployment is associated with a lower income share for the richest fifth and a higher share for the second poorest fifth. For the remaining groups, the coefficients are not precisely estimated. It is quite surprising that, controlling for real interest rates, inflation and real GDP growth, unemployment benefits the second poorest fifth and hurts the richest fifth. As it happens this result is not robust to variations in the choice of regressors. For instance, excluding either 
the inflation rate or the real interest rate reverses the sign of the unemployment coefficient in richest quintile group's equation (results not shown). The positive association between the income share of the second poorest fifth and the unemployment rate is robust across specifications however.

Higher inflation appears to be associated with increases in the income share of the richest fifth and decreases in the shares of the other groups, although only in case of the second and third quintile groups are the coefficient estimates large relative to their standard errors. The coefficients on real interest rates have the same pattern as the ones for inflation and, except for the fourth quintile, are fairly precisely estimated. Finally, real GDP growth appears to be associated with increases in the share of the poorest fifth but hardly at all for the other income groups. We now contrast these results with those derived from the methods we propose.

\section{III.2 Regressing income distribution parameters on macroeconomic variables}

Are the variables stationary? The most commonly used tests for the stationarity of economic time series take the unit root case to be the null hypothesis. While conventional, this choice of null hypothesis makes it very difficult to reject the unit root hypothesis. This is not in the spirit of classical test theory. As there is plenty of evidence to suggest that standard unit root tests have low power (Kwiatkowski et al.; 1992), the choice of the unit root as the null hypothesis can be misleading. Choosing stationarity as the null hypothesis instead avoids these problems and is more in line with the spirit of classical test theory. Such a test has been developed by Kwiatkowski et al. (1992). The test is that, for a decomposition of the variable $y_{t}$ into a random walk term and a stationary error (and an optional deterministic trend), the variance of the random walk term is zero.

The Kwiatkowski et al. (1992) test statistics are shown in Table 3. The Singh-Maddala parameters are based on sample estimates with a heteroskedastic error term, $\hat{\theta}_{t}=\theta_{t}+\eta_{t}$, where $\eta_{t} \sim N\left(0, \Omega_{t}\right)$. This suggests that, in order to purge the series of the heteroskedasticity due to sampling, one should normalize the estimate of $a$ by the estimated standard error of $\hat{\omega}_{1 t}$, and examine the series $\left\{\hat{a}_{t} / \hat{\omega}_{t}\right\}$ (and with analogous normalization for $q$ ). We show the test statistics for the normalised series of $a$ and $q$ below those for the 'raw' sample estimates.

[Table 3 about here.] 
The evidence concerning the stationarity of the variables is in most cases mixed. For instance, the heteroskedasticity-corrected Singh-Maddala $a$ parameter yields a test statistic of 0.378 (max lag length 1) in the level stationary case, which is lower than the 5 percent critical value of 0.463 , but in the trend stationary case the test statistic is 0.217 , higher than the critical value. Because the evidence is mixed, we do not reject the null hypothesis that the variables are stationary. We thus interpret the evidence as not being supportive of the alternative hypothesis of non-stationarity and proceed to model the variables as $I(0)$ processes. ${ }^{6}$

\section{Time-series regressions}

[Table 4 about here.]

The SUR estimates from regressions of the Singh-Maddala parameters $a$ and $q$ against the macro variables are shown in Table 4. We estimated the parameters in levels as we found the evidence suggestive of stationarity rather than a unit root. Because of the transformation of the GLS problem in equation 12 , we measured each variable as a deviation from its mean. We show estimates for three sets of models. Model A has as regressors only the overall unemployment rate and the inflation rate. In model B we add the real interest rate and in model $\mathrm{C}$ we add the real GDP growth rate as well.

Considering the joint significance of the covariates, unemployment clearly has a jointly statistically significant effect on the Singh-Maddala parameters in each of the three models A-C. The F-statistic of the hypothesis that the unemployment coefficients are zero is in all three cases very large, suggesting the hypothesis can safely be rejected. Inflation, on the other hand, fails to be statistically significant even at the 10 percent level. Adding the real interest rate does not alter this, although the overall performance of the estimated equations as measured by the likelihood ratio test of A against B suggests that B does indeed provide a significantly better fit (at the 10 percent level). When the real GDP growth rate is added to the regressors (model C), this again alters the picture. Inflation remains statistically insignificant, but the unemployment rate, the real interest rate, and the real GDP growth rates are statistically significant. The likelihood ratio test suggests that model C is superior to models A and B.

The estimated coefficients are not very informative about the influence on inequality of a change in unemployment or some other macro variable. In order to illuminate these effects, we illustrate 
them graphically. In particular, we plot the Gini coefficient against the unemployment rate, the inflation rate, and both: see Figure 6. The graphs correspond to the observed ranges of variation of the regressors over the sample period (recall that we measure all covariates as deviations from their sample means).

[Figure 6 about here.]

When $a$ and $q$ are regressed on just the inflation and unemployment rates (model A), variations in the unemployment rate appear to have much larger effects than inflation: see Figure 6(a) and 6(b). However, when the real interest rate in included among the regressors (model B), variations in unemployment generate slightly smaller changes in inequality. The Gini-profile of unemployment becomes (slightly) negative once the rate of real GDP growth is added as a regressor (model C). The Gini-profile of inflation, on the other hand, is positive in models A and C. By contrast, in model B - without real GDP growth - the Gini coefficient has a U-shaped profile with respect to inflation, decreasing at very low levels of inflation and increasing at high rates. The Gini profile of the real interest rate is even more erratic than that for unemployment. Based on the parameter estimates from model $\mathrm{B}$, increases in real interest rates are associated with declines in inequality whereas the reverse is true based on estimates in model C. Finally, higher real GDP growth rates are associated with increased inequality.

[Figure 7 about here.]

In Figure 7 we show the joint impact of macroeconomic variations on the Gini coefficient, based on model C. (Figure 7(a) show the contours of the Gini coefficient as a function of unemployment and inflation whereas Figure 7(b) shows the contours as a function of unemployment and real interest rates.) Reducing unemployment at low levels of inflation leads to declines in inequality, but inequality is fairly flat with respect to variations in the unemployment rate at high levels of inflation, as witnessed by the flattening out of the contours. Reductions in the unemployment rate are associated with increased inequality holding real interest rate constant also.

[Figure 8 about here.] 
In order to provide a richer picture of the distributional patterns associated with macroeconomic activity and to further demonstrate the potential of our approach, we show how variations in the covariates impact on the income shares of the poorest and richest fifths. Figure 8 shows the income share of the two income groups as functions of unemployment and inflation, whereas Figure 9 shows the bivariate income share contours with respect to unemployment and inflation and unemployment and real interest rates. The income shares of the poorest and richest income groups are mirror images of each other (cf. the top two and bottom two pictures in Figure 8) while exhibiting the same instability of the profiles as did the univariate Gini profiles. There is more variation in the contours of the poorest and the richest groups' income shares. The direction of change in the contours of each set of income shares is reversed between the top and bottom rows, but the curvature and the spacing of the contours is a little different.

[Figure 9 about here.]

Compared to the results of explaining the quintile group shares directly, our preferred approach reveals both similarities and differences. While we do not find strong evidence in favour of nonstationarity our dependent variables could have unit roots (at least in principle), making it meaningful to test for evidence of them. The impacts on inequality of variations in particular covariates is sensitive to the choice of regressors used in the model. The effects of unemployment and inflation in particular - the starting point in the literature we contribute to - depend very much on what other variables are controlled for. This was also true of the quintile group share estimates. Our approach also allows for quite flexible functional form for the inequality profiles of the covariates, as it is the parameters rather than the inequality indices themselves that we are explaining. In particular, our analysis revealed that the inequality impact of a given change in a covariate may depend both its own value and of the values of the other covariates.

\section{Discussion and concluding comments}

We have examined the extent to which changes in macroeconomic variables, in particular in the rate of unemployment and inflation, are associated with changes in income inequality in the United 
Kingdom from 1961 to 1991 . We approached the issue using both 'first generation' econometric methods - regressing quintile income shares on macroeconomic variables and, inspired by dynamic' econometrics, testing for the stationarity of the variables.

The analysis reveals that our proposed new methods have several advantages compared to the earlier approaches in which inequality indices were modelled directly. Standard methods can be used to examine the stationarity of each series and, because the regressands are distribution function parameters, the predicted patterns of inequality remain within their logical bounds. Our method also allows for the effect of the covariates on inequality to assume quite flexible functional forms despite the fact that our estimating equations are linear.

Our findings suggest that the impact of macroeconomic fluctuations on inequality are complex and depend on what other variables are included in the model. There appears to be no simple answer to the question of whether unemployment or inflation is more harmful for the living standards of the least well off in the UK.

\section{Acknowledgements}

Jäntti acknowledges support from the Yrjö Jahnsson foundation and the Academy of Finland. Jenkins is supported by core funding funding ISER receives from the Economic and Social Research Council and the University of Essex. Jenkins also acknowledges support from the TMR Network 'Living standards, inequality and taxation', Contract No. ERBFMRXCT 980248. 


\section{References}

Ashworth, J. (1994). An empirical examination of macroeconomic activity and income distribution in the United States, Economics Working Paper 130, University of Durham, Durham.

Beach, C. M. and McWatters, C. J. (1990). Factors behind the changes in Canada's family income distribution and the share of the middle class, Relation Industrielles 1: 118-133.

Björklund, A. (1991). Unemployment and income distribution: time-series evidence from Sweden, Scandinavian Journal of Economics 93: 457-465.

Blank, R. and Blinder, A. (1986). Macroeconomics, income distribution and poverty, in S. Danziger and D. Weinberg (eds), Fighting Poverty, Harvard University Press, Cambridge.

Blinder, A. and Esaki, H. (1978). Macroeconomic activity and income distribution in the postwar United States, The Review of Economics and Statistics 60(4): 604-609.

Brachman, K., Stich, A. and Trede, M. (1996). Evaluating parametric income distribution models, Allgemeines Statistisches Archiv 80: 285-298.

Cutler, D. M. and Katz, L. F. (1991). Macroeconomic performance and the disadvantaged, Brookings Papers on Economic Activity 10(2): 1-74.

Dagum, C. (1980). The generation and distribution of income, the Lorenz curve and the Gini ratio, Economique Appliquée 33(2): 327-367.

Das, S. P. (1993). New Perspectives on Business Cycles, Edward Elgar, Aldershot, England.

Goodman, A. and Webb, S. (1994). For richer, for poorer: The changing distribution of income in the United Kingdom, 1961-91, Commentary 42, Institute for Fiscal Studies, London.

Hendry, D. (1995). Dynamic Econometrics, Oxford University Press, Oxford.

Jenkins, S. (1999). sg106 Fitting Singh-Maddala and Dagum distributions by maximum likelihood (smfit, dagumfit), Stata Technical Bulletin STB-48: 19-25. 
Jäntti, M. (1994). A more efficient estimate of the effects of macroeconomic activity on the distribution of income, Review of Economics and Statistics 76(2): 372-378.

Kwiatkowski, D., Phillips, P., Schmidt, P. and Shin, Y. (1992). Testing the null hypothesis of stationarity against the alternative of a unit root: How sure are we that economics time series have a unit root?, Journal of Econometrics 54(1-3): 159-178.

Leslie, D. and $\mathrm{Pu}$, Y. (1995). Unions and the rise in wage inequality in Britain, Applied Economics Letters 2(8): 266-270.

McDonald, J. B. (1984). Some generalized functions for the size distribution of income, Econometrica 52(3): 647-663.

Mocan, H. N. (1999). Structural unemployment, cyclical unemployment and income inequality, Review of Economics and Statistics 81(1): 122-135.

Nolan, B. (1988-89). Macroeconomic conditions and the size distribution of income: evidence from the United Kingdom, Journal of Post Keynesian Economics 11(2): 196-221.

Parker, S. (1996). Explaining the determinants of US income inequality, 1948-90, Economics Working Paper 163, University of Durham, Durham.

Parker, S. C. (1998-99). Income inequality and the business cycle: a survey of the evidence and some new results, Journal of Post Keynesian Economics 21(2): 201-225.

Parker, S. C. (2000). Opening a can of worms: the pitfalls of time-series regression analyses of income inequality, Applied Economics 32(2): 221-230.

Persson, T. and Tabellini, G. (1994). Is inequality harmful to growth?, American Economic Review 84(3): 600-621.

Singh, S. K. and Maddala, G. S. (1976). A function for the size distribution of incomes, Econometrica 44(5): 963-970.

Wilfling, B. and Krämer, W. (1993). The Lorenz-ordering of Singh-Maddala income distributions, Economics Letters 43: 53-57. 


\section{Notes}

${ }^{1}$ This view was expressed by Mr. Tietmeyer in an interview in the Finnish magazine Suomen Kuvalehti, 3/98. In this view, Mr Tietmeyer is not alone. The inspiration of an early study that addressed this topic was the claim that inflation is 'the cruellest tax' on the poor (see Blinder and Esaki; 1978).

${ }^{2}$ The US studies include Blank and Blinder (1986) who also examine the poverty rate, and Cutler and Katz (1991), who also examine the effects on consumption inequality. The studies by e.g. Mocan (1999), Ashworth (1994) and Parker (1996) used methods of dynamic econometrics

${ }^{3}$ See McDonald (1984). Wilfling and Krämer (1993) provide a characterization of the conditions for Lorenz dominance in terms of $a$ and $q$.

${ }^{4}$ The parameter estimates were obtained using Stata programs written by one of the authors (Jenkins; 1999).

${ }^{5}$ Since $\sum_{j=1}^{5} q_{j t} \equiv 100$, it follows that $\sum_{j=1}^{5} \beta_{1 j}=100$ and $\sum_{j=1}^{5} \beta_{k j}=0$ for the regressors. Also, since $\sum_{j=1}^{5} \varepsilon_{j t} \equiv 0$, the variance of the residual in the omitted equation is $\sigma_{5}^{2}=E\left(\sum_{j=1}^{4} \varepsilon_{j t}\right)^{2}$.

${ }^{6}$ Were we to abandon stationarity, the series would obviously need to be modeled using cointegration techniques. Given, among other problems, that we have a limited number of time periods $(T=31)$ such an undertaking would not be very likely to yield robust results. 


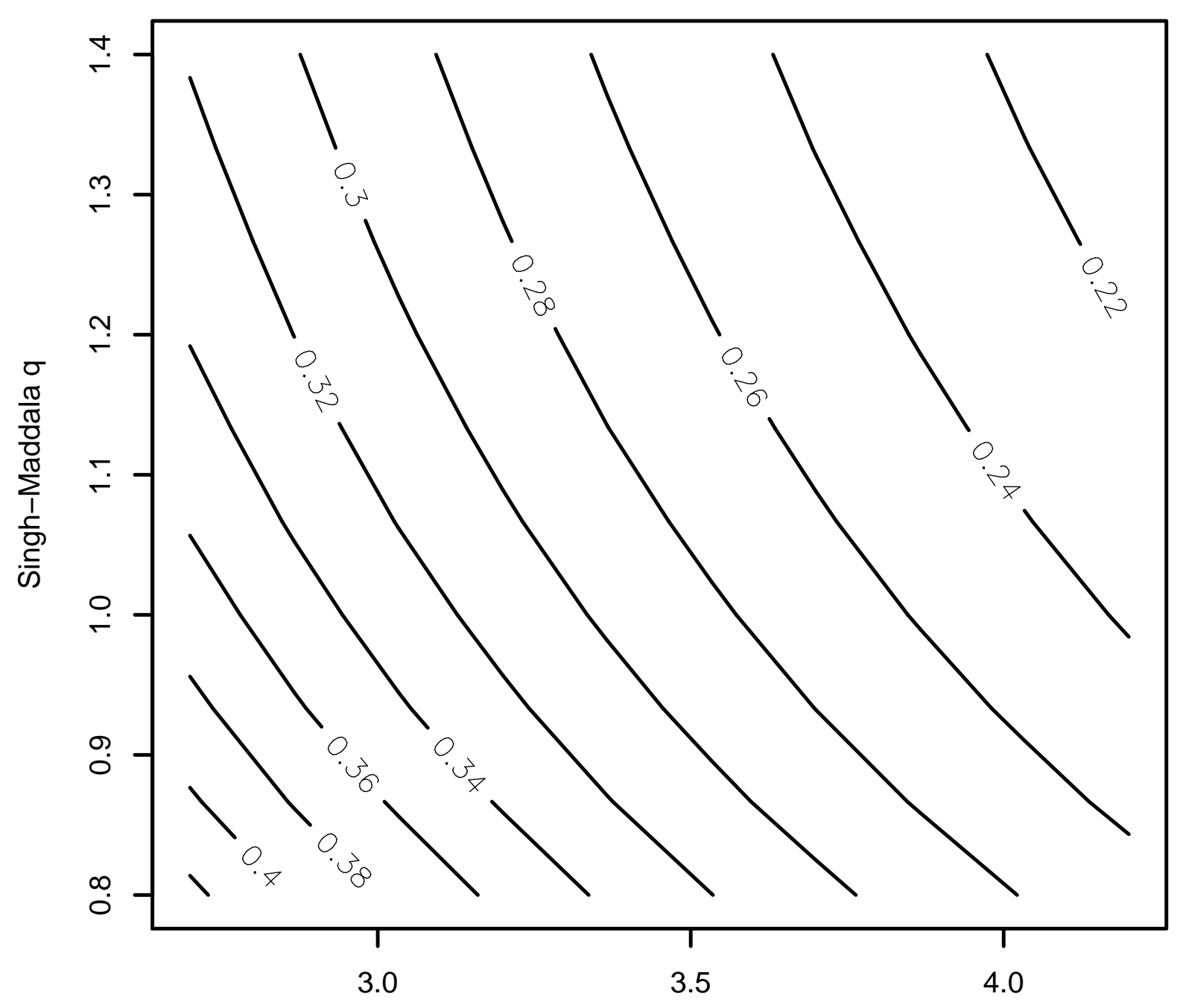

Singh-Maddala a 
Figure 2 Quintile group income shares for Singh-Maddala distribution function parameters

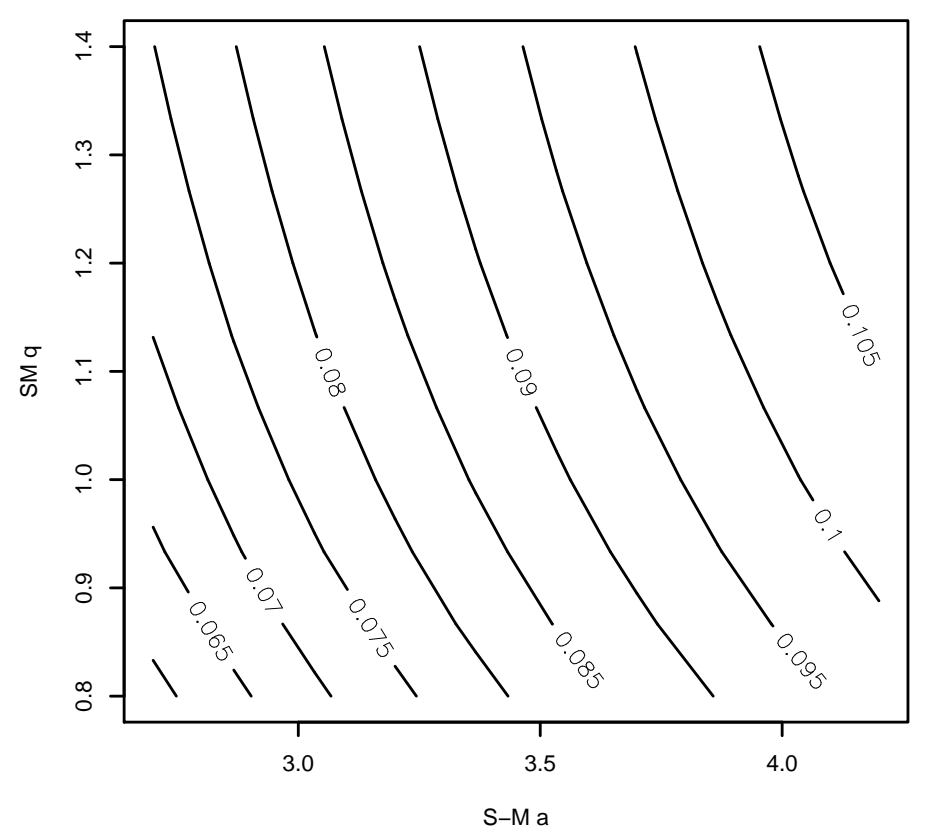

(a) Poorest fifth

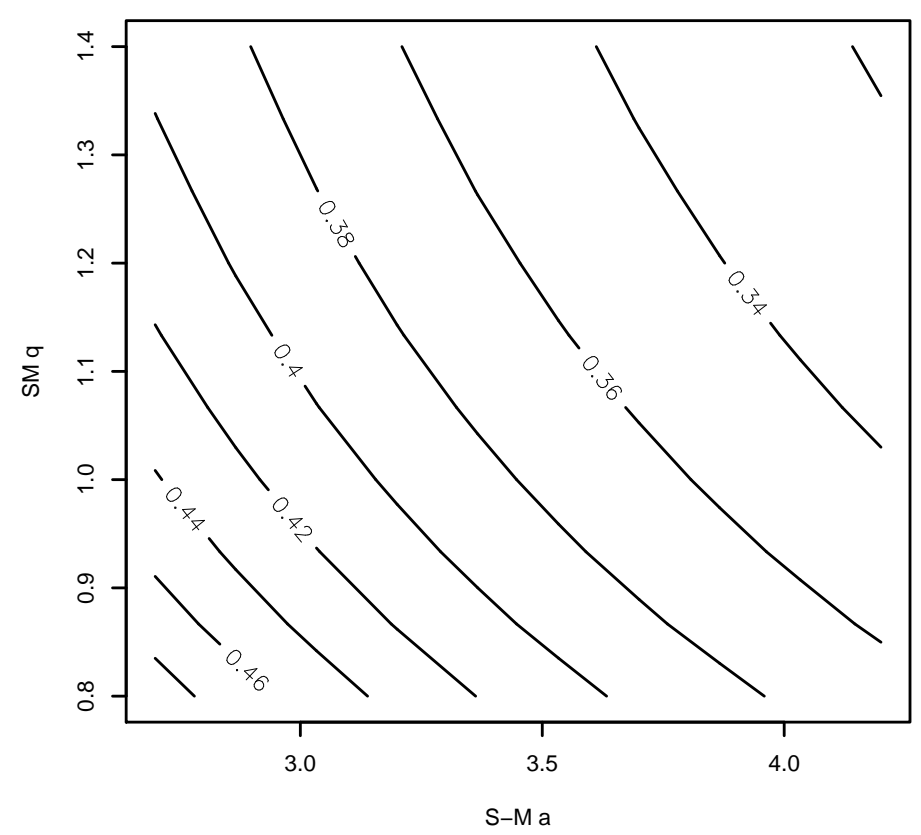

(b) Richest fifth 
Figure 3 Macroeconomic conditions in the United Kingdom, 1961-1991

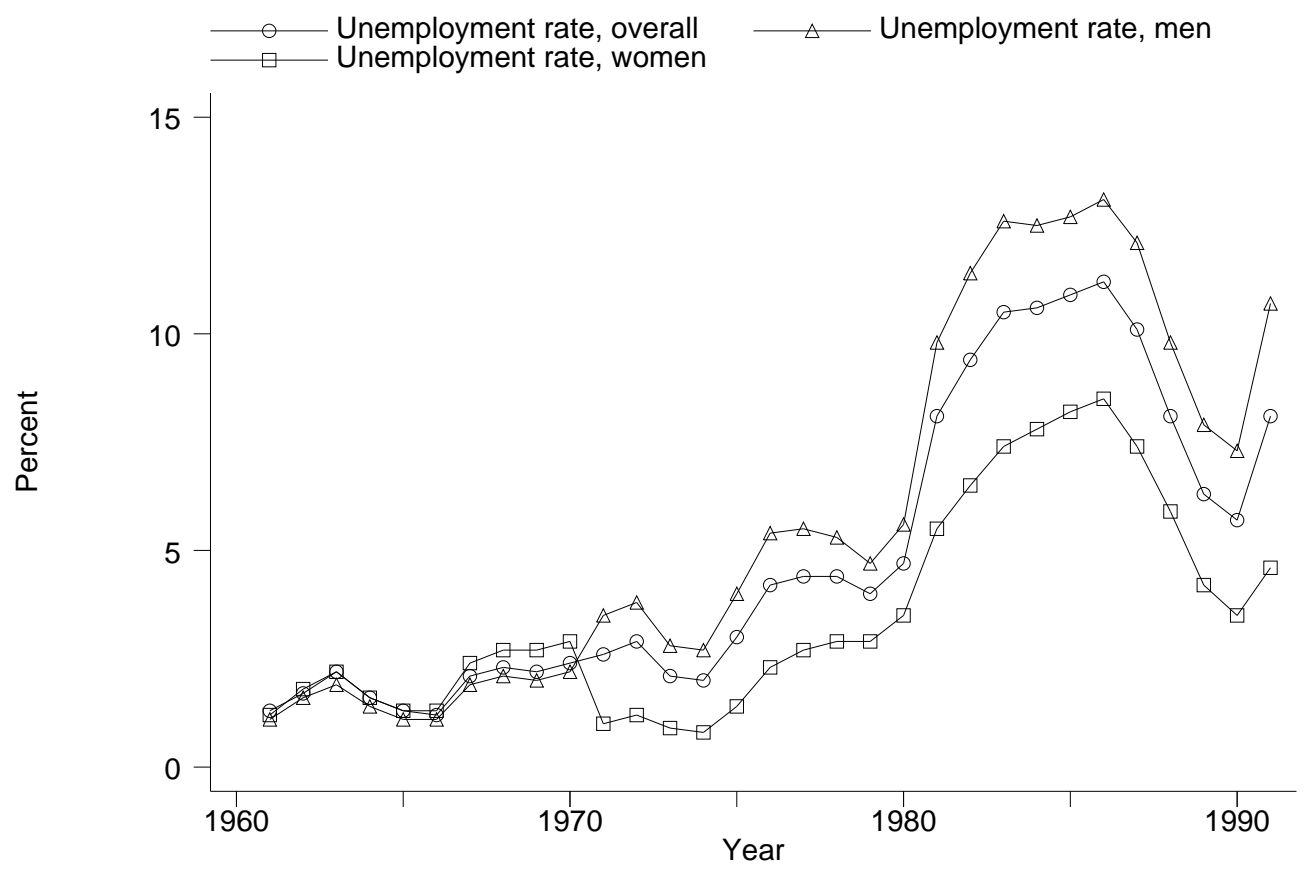

(a) Unemployment

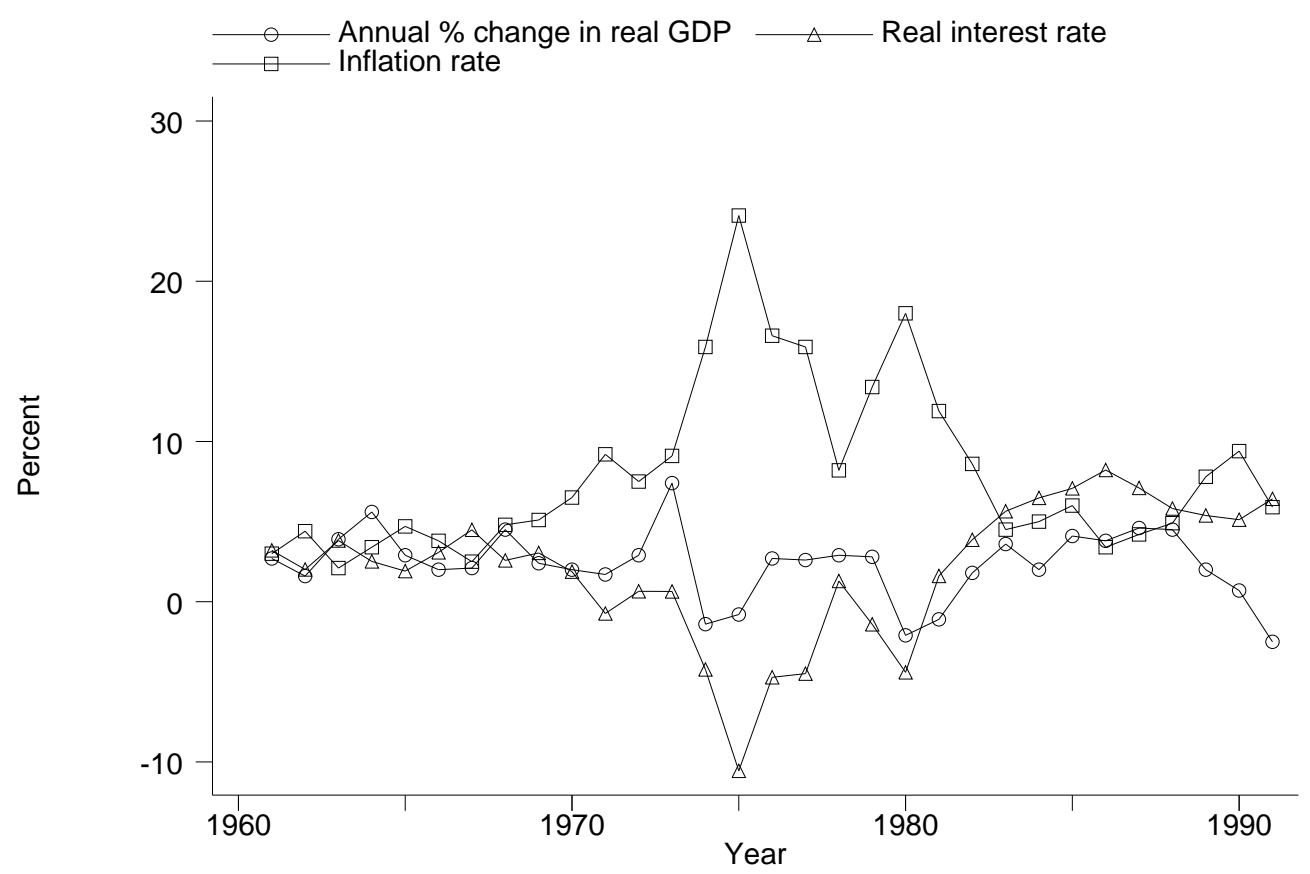

(b) Real GDP growth, Inflation and Real interest rate 


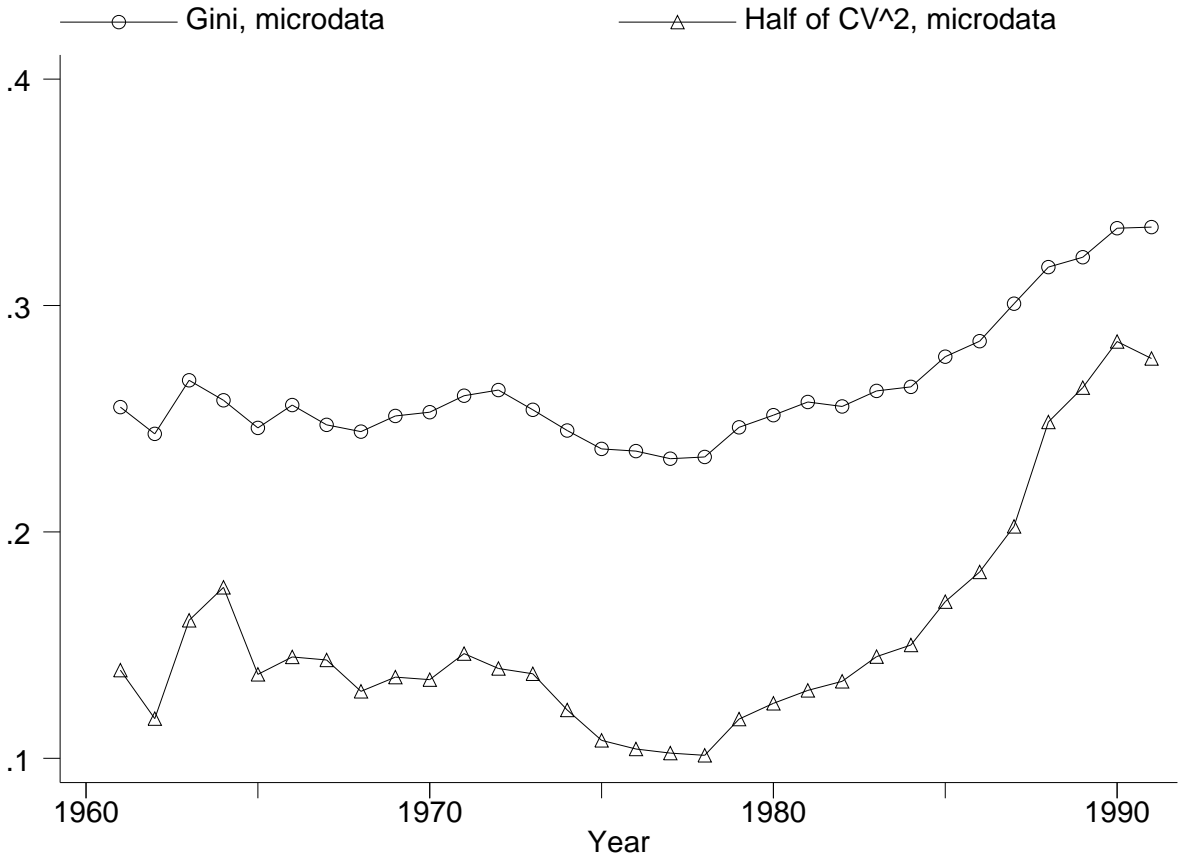

(a) Gini and $C V^{2} / 2$

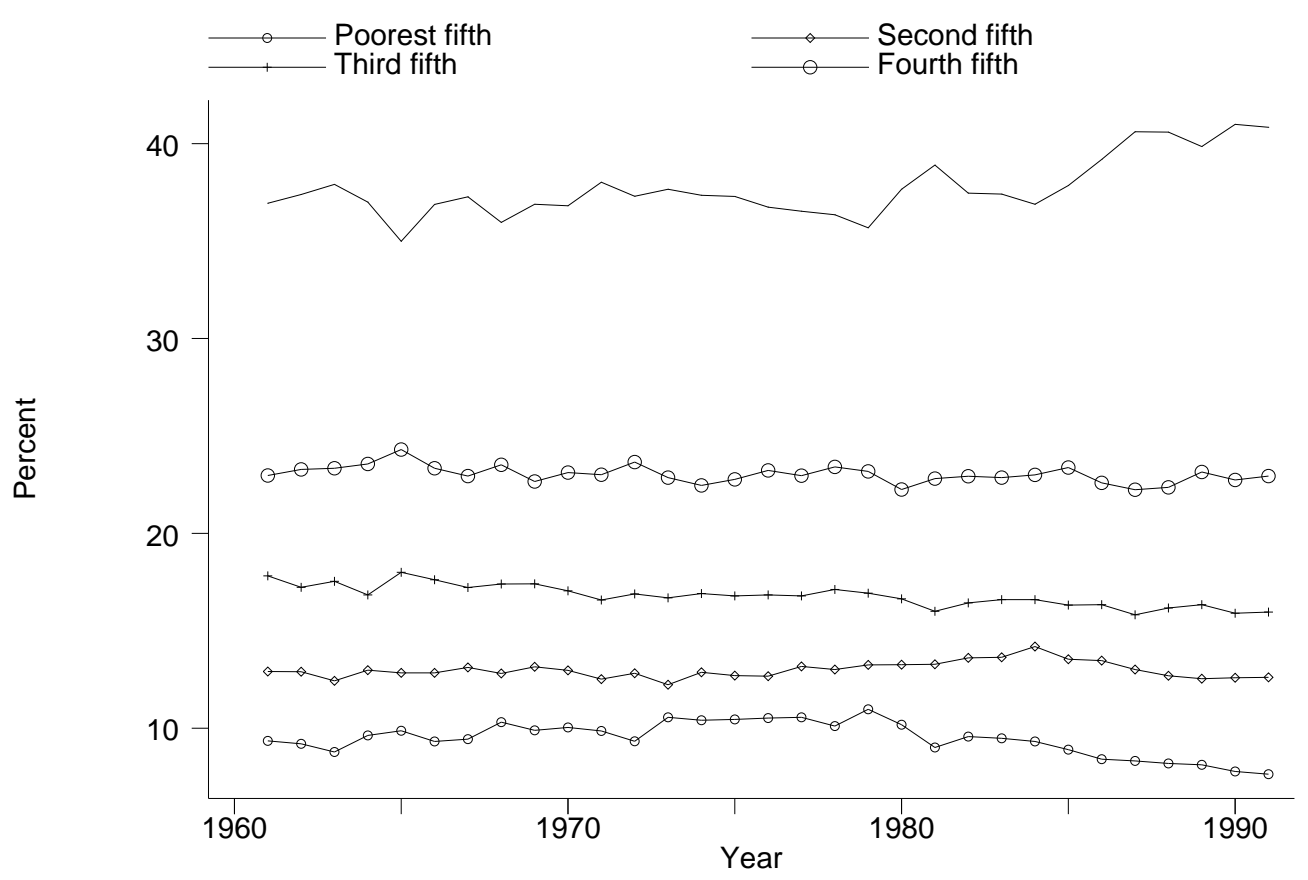

(b) Quintile group shares 


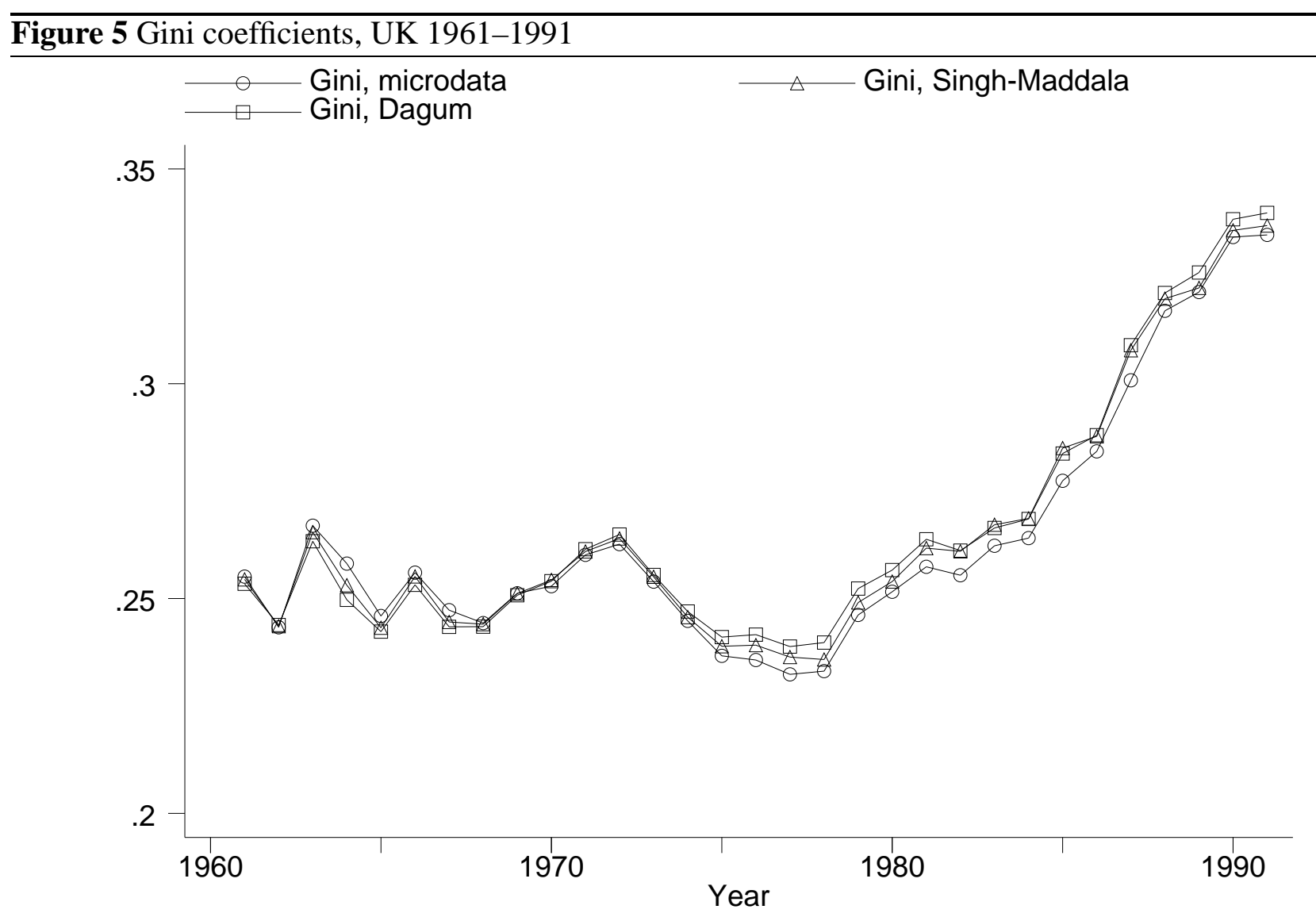

Note: The Gini coefficient series were estimated non-parametrically directly from the FES microdata and parametrically from the estimated parameters of the Singh-Maddala and Dagum distribution functions. 
Figure 6 Impact on Gini coefficient of the rates of overall unemployment, inflation, real interest, and real GDP growth - Singh-Maddala model estimates

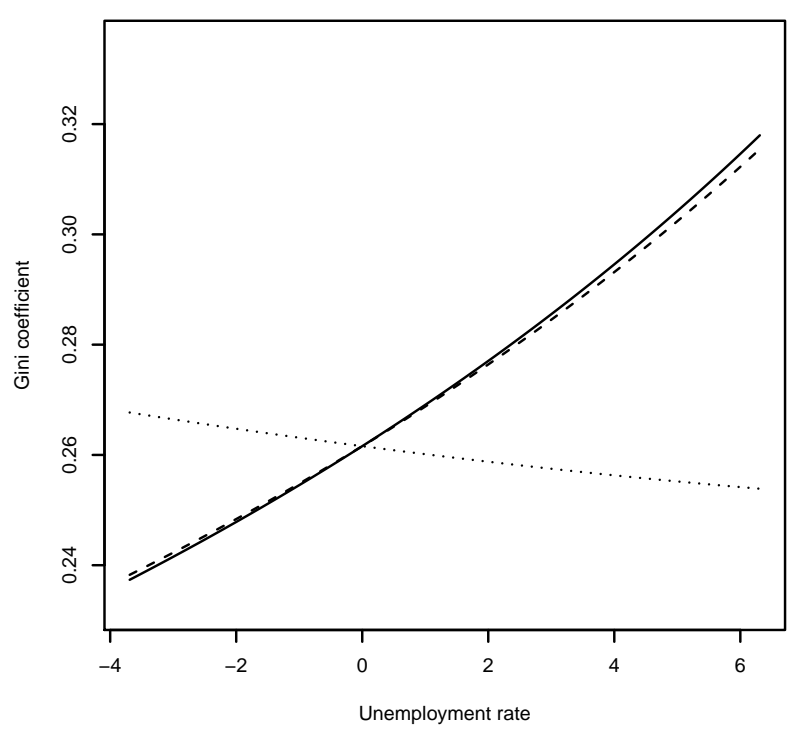

(a) Unemployment rate

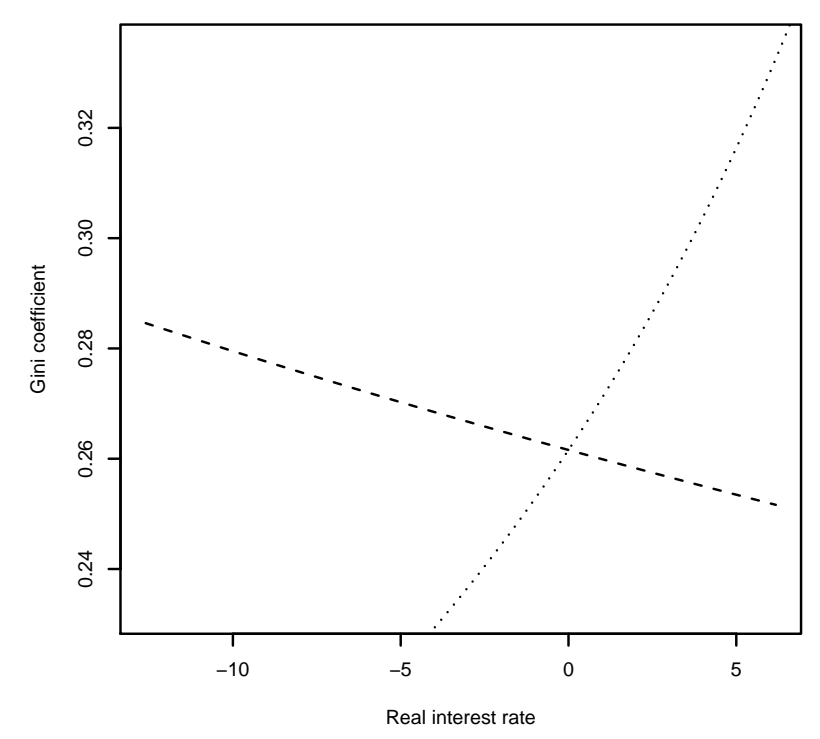

(c) Real interest rate

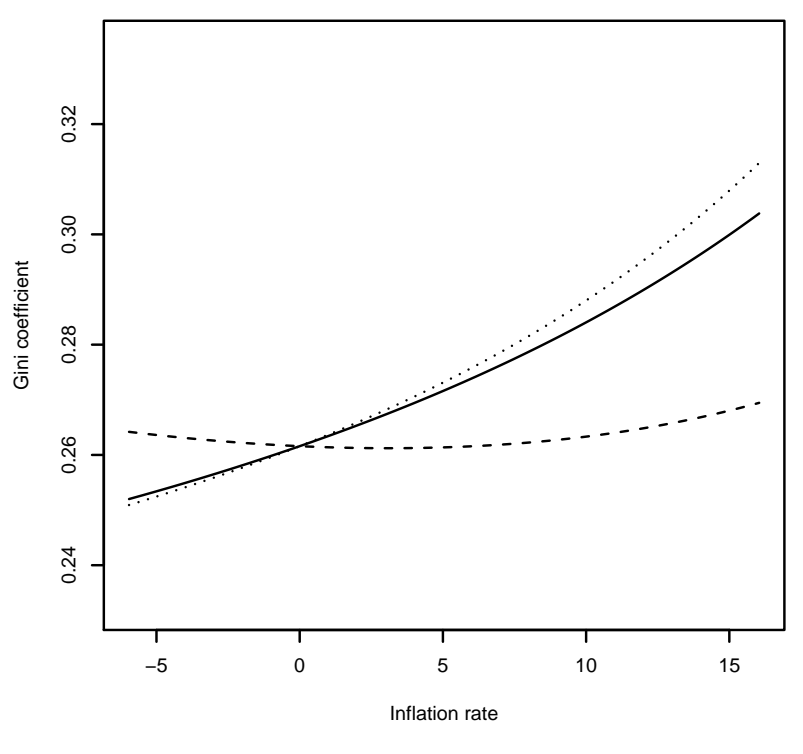

(b) Inflation rate

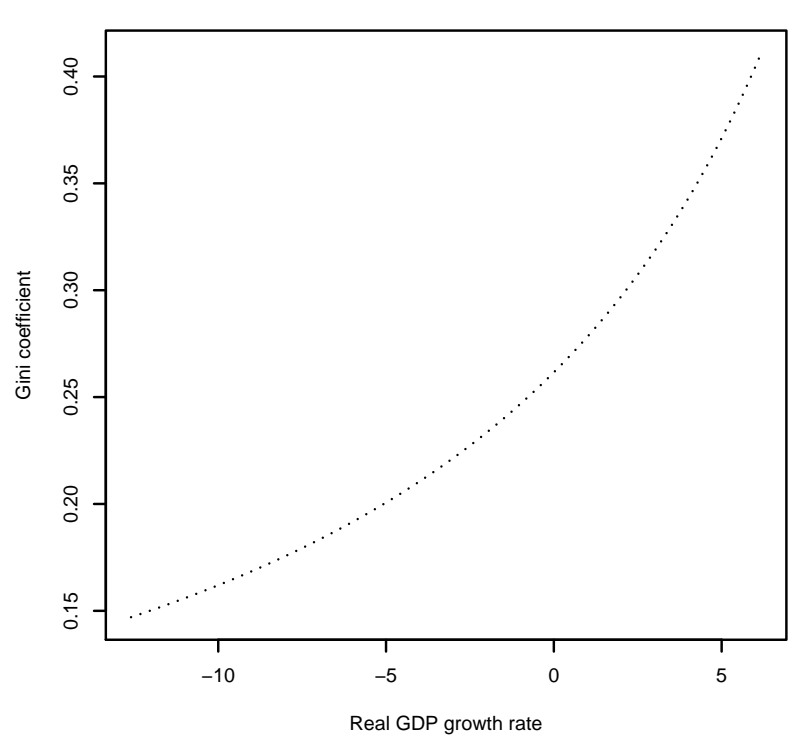

(d) real GDP growth rate

Model A: — Model B: - - Model C:

Note: Covariates are measured in terms of deviations from their mean values. See Table 4 for estimation results. 
Figure 7 The joint impact of variations in overall unemployment, inflation and the real interest rate on the Gini coefficient - estimates of Singh-Maddala model C

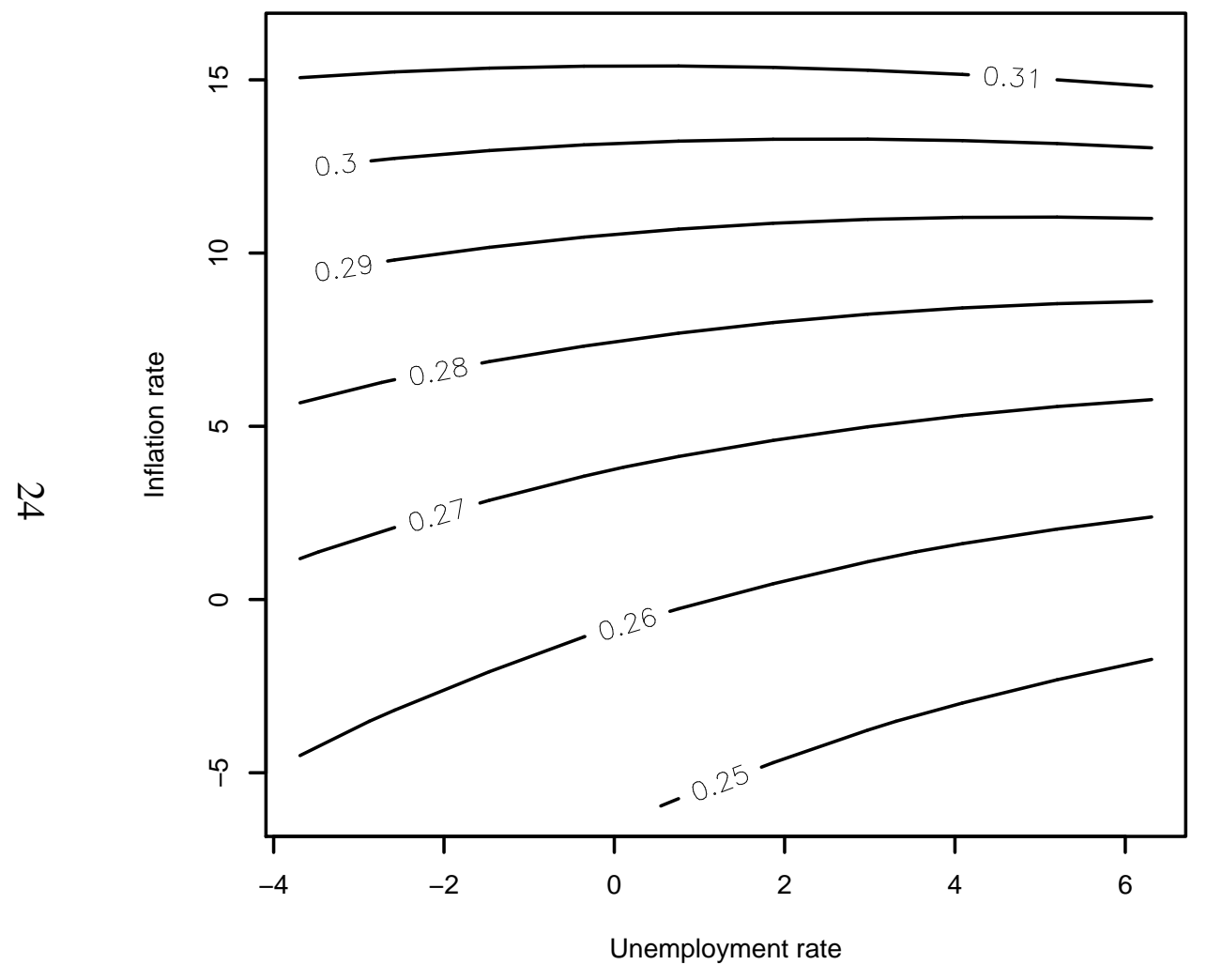

(a) Unemployment and inflation

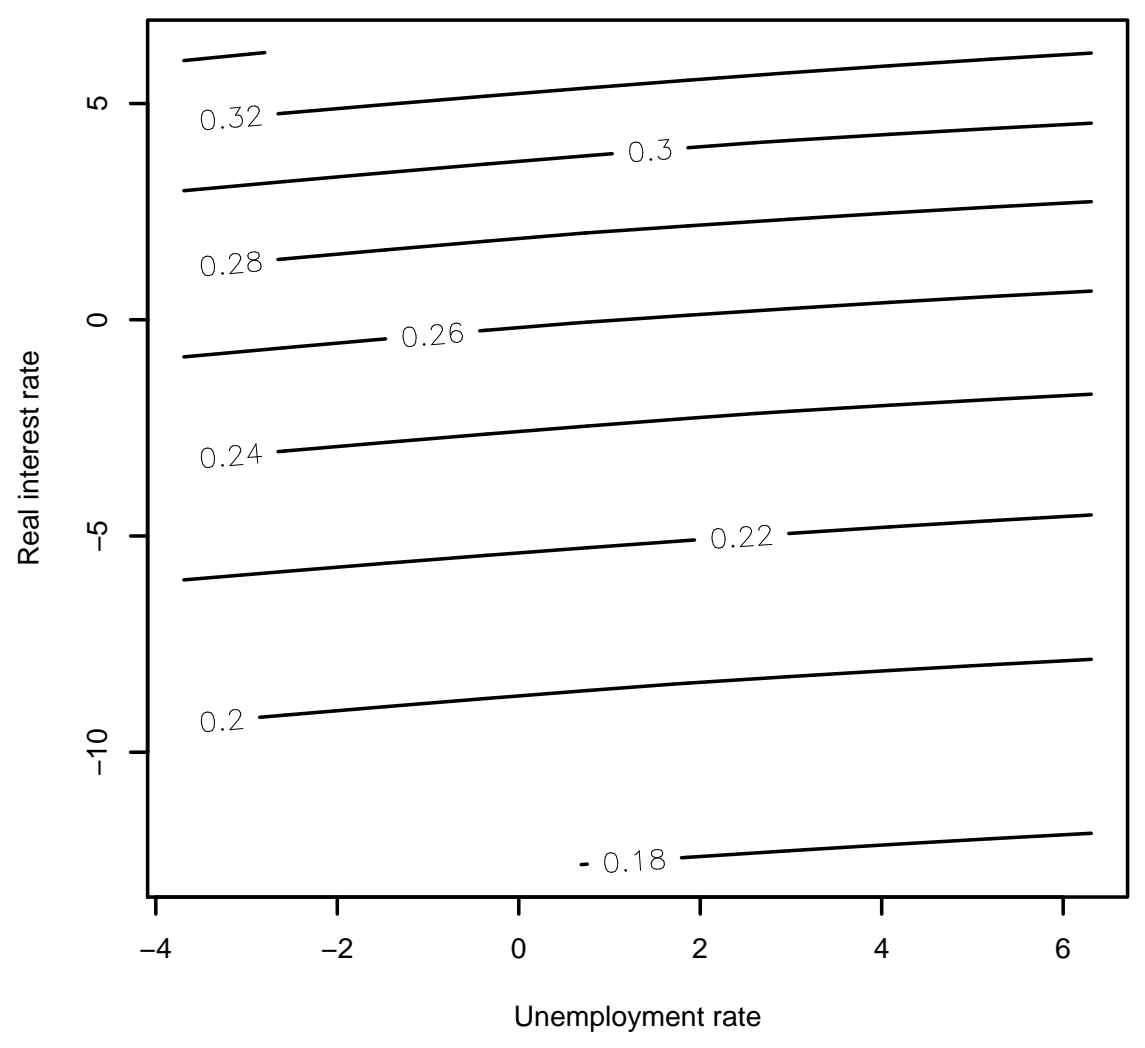

(b) Unemployment and real interest rate

Note: All covariates are measured in terms of deviations from their mean values. See Table 4, Model C for estimation results. 
Figure 8 The impact of overall unemployment and inflation on the income shares of the poorest and the richest fifths - Singh-Maddala model estimates

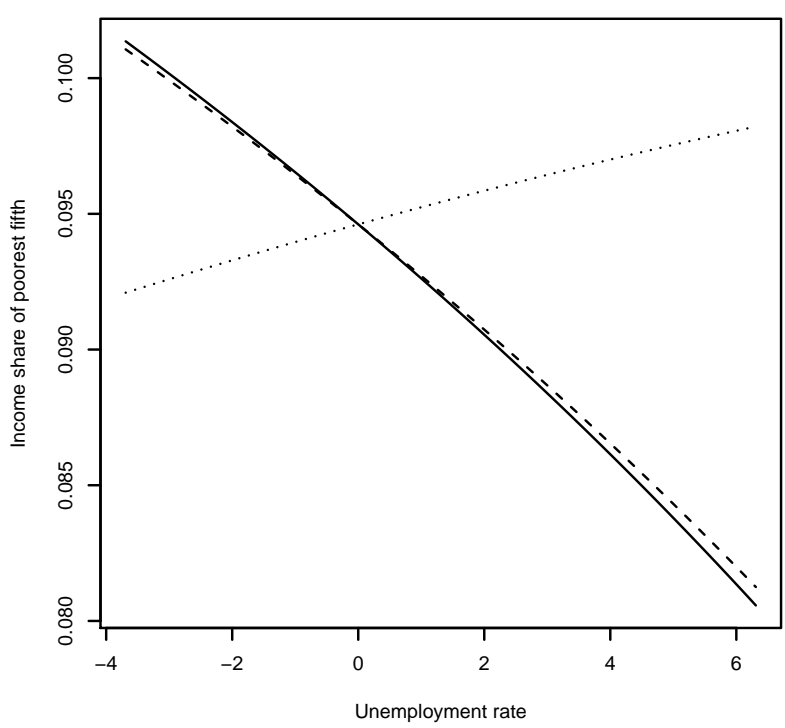

(a) Poorest: Unemployment

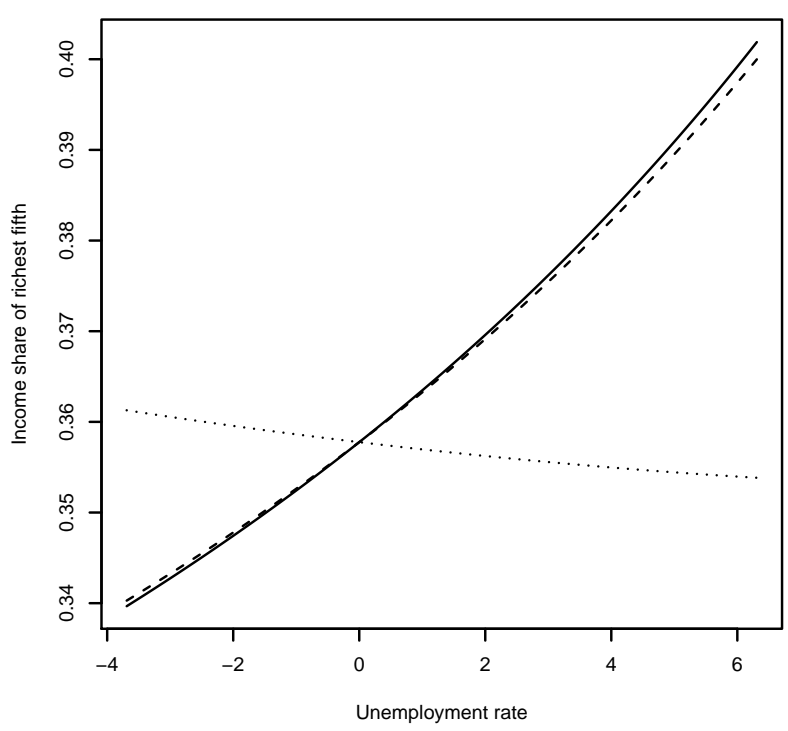

(c) Richest: Unemployment

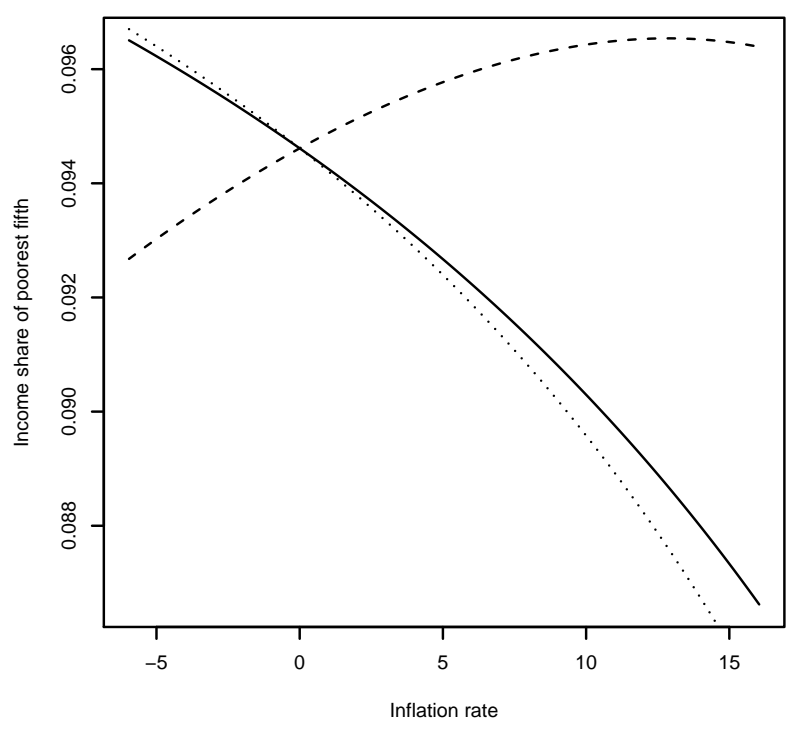

(b) Poorest: Inflation

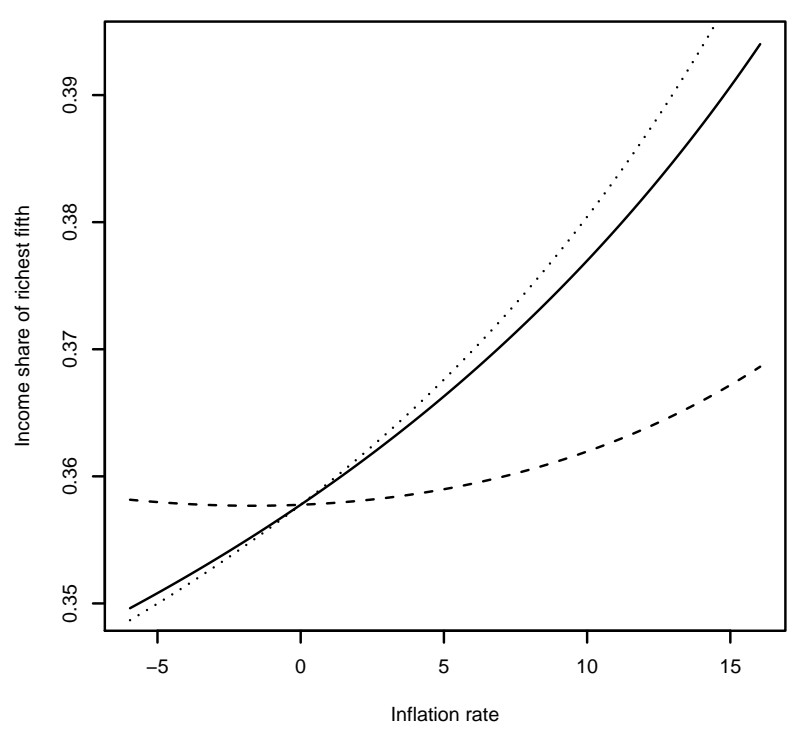

(d) Richest: Inflation

Model A: — Model B: --- Model C: .....

Note: See Table 4 Model C for estimation results. 
Figure 9 The joint impact of overall unemployment, interest rates and inflation on the income shares of the poorest and the richest fifths - estimates of Singh-Maddala model

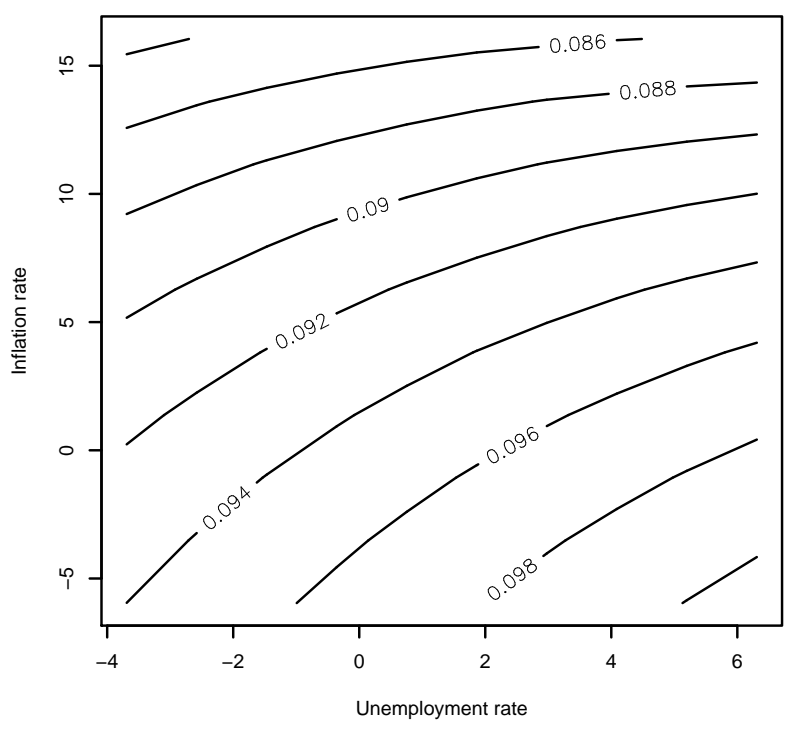

(a) Poorest: Unemployment and inflation

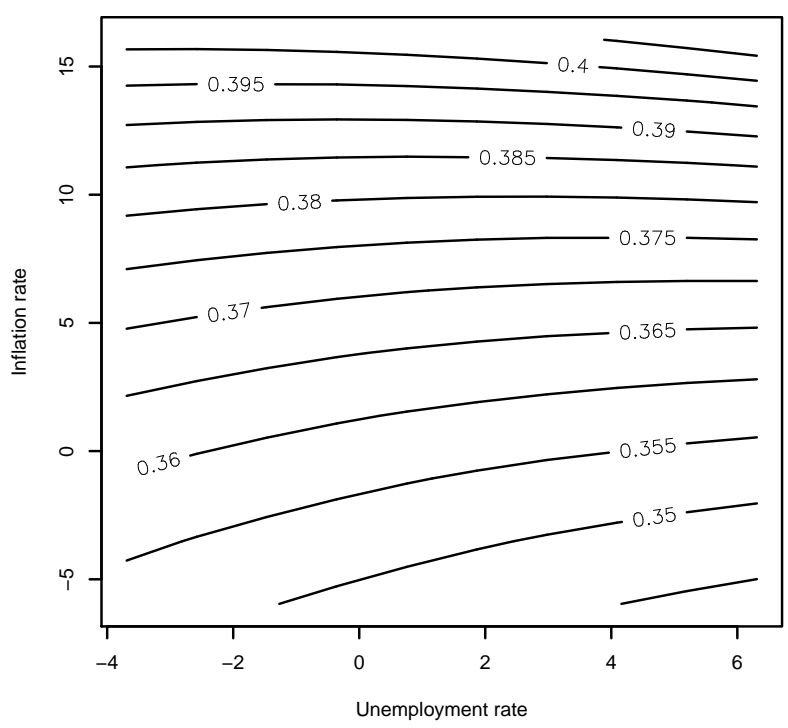

(c) Richest: Unemployment and inflation

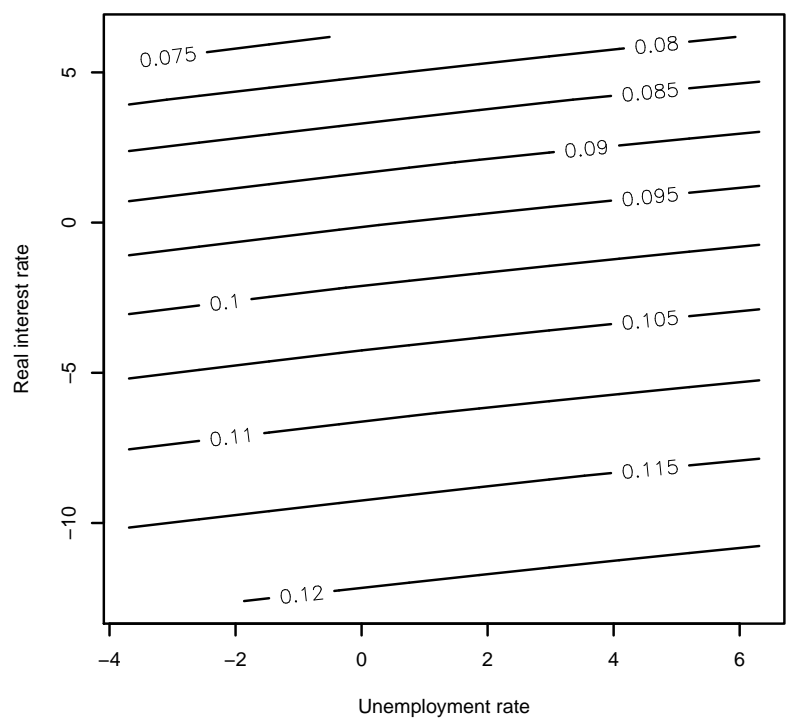

(b) Poorest: Unemployment and real interest rate

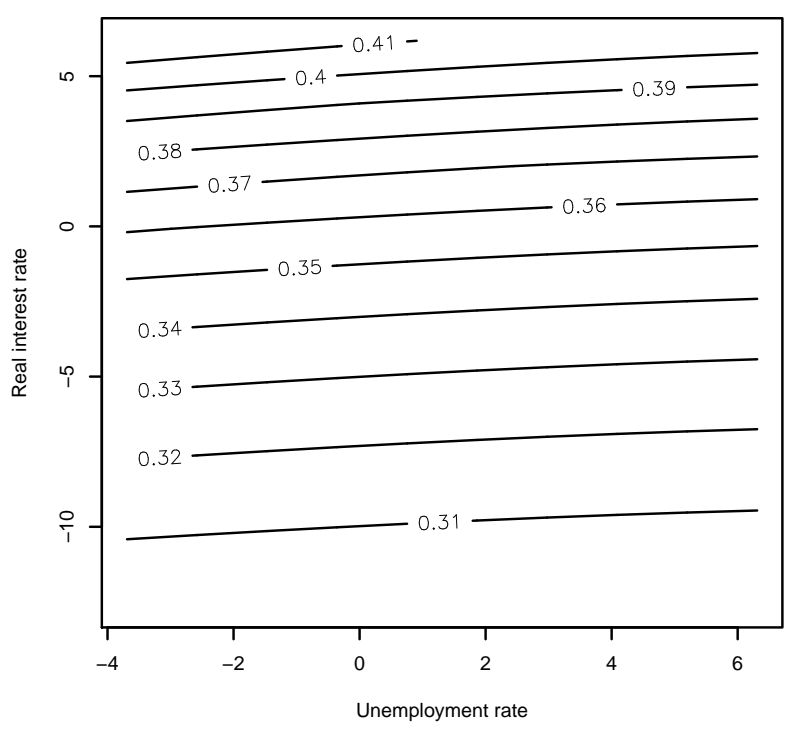

(d) Richest: Unemployment and real interest rate

Note: Pictures show contours of the income share of the poorest (solid line) and richest (dashed line) fifths of the population for different values of the unemployment rate and the inflation and real interest rates. See Table 4 for estimation results. 


\begin{tabular}{|c|c|c|}
\hline & Singh-Maddala & Dagum \\
\hline C.d.f. & $\begin{array}{l}F(y ; a, b, q)=1-\left[1+(y / b)^{a}\right]^{-q} \\
y \geq 0, a>0, b>0, q \geq 1 / a\end{array}$ & $\begin{array}{l}F(y ; b, d, h)=\left(1+h y^{-d}\right)^{-b} \\
y>0, b>0, d>0, h>0\end{array}$ \\
\hline$p$ th Quantile & $y_{p}=b\left[(1-p)^{-1 / q}-1\right]^{1 / a}$ & $y_{p}=h^{1 / d}\left(p^{-1 / b}-1\right)^{-1 / d}$ \\
\hline$r$ th Moments & $\mu_{r}=b^{r} \frac{\operatorname{Bet} a(1+r / a, q-r / a)}{\operatorname{Beta}(1, q)}$ & $\mu_{r}=b h^{r / d} \operatorname{Bet} a(1-1 / d, b+1 / d), \quad d>1$ \\
\hline Gini coefficient & $G[F(y ; a, b, q)]=1-\frac{\operatorname{Beta}(q, 2 q-1 / a)}{\operatorname{Bet} a(q-1 / a, 2 q)}$ & $G\left[F(y ; b, d, h)=\frac{\operatorname{Beta}(b, 2 b+1 / d)}{\operatorname{Beta}(2 b, b+1 / d)}\right.$ \\
\hline Lorenz curve & $\begin{array}{l}L[p ; F(y ; a, b, q)]=z \int_{0}^{p}\left[(1-F)^{-1 / q}-1\right]^{1 / a} \\
z=[\operatorname{Beta}(1+1 / a, q-1 / a) / \operatorname{Beta}(1, q)]^{-1}\end{array}$ & $L[p ; F(y ; b, d, h)]=B\left(F^{1 / b} ; b+1 / d, 1-1 / d\right), \quad d>1$ \\
\hline
\end{tabular}

Note: $\operatorname{Bet} a(\cdot)$ is the Beta function and $B(\cdot ; \cdot)$ is the Beta distribution function. Source: McDonald (1984) and Dagum (1980). 
Table 2 Regressions of quintile group income shares on macroeconomic variables

\begin{tabular}{lcccccc}
\hline & \multicolumn{5}{c}{ Quintile group } & Joint \\
\cline { 2 - 6 } Explanatory variable & Poorest & Second & Third & Fourth & Richest & test \\
\hline Unemployment (all) & 0.050 & 0.154 & -0.030 & -0.020 & -0.154 & 9.13 \\
& $(0.059)$ & $(0.036)$ & $(0.036)$ & $(0.046)$ & $(0.129)$ & \\
Inflation & & & & & & \\
& -0.095 & -0.113 & -0.149 & -0.061 & 0.418 & 3.85 \\
Real interest rate & $(0.069)$ & $(0.042)$ & $(0.042)$ & $(0.053)$ & $(0.150)$ & \\
& & & & & & \\
real GDP growth & 0.299 & -0.154 & -0.178 & -0.060 & 0.691 & 3.28 \\
& $0.095)$ & $(0.059)$ & $(0.058)$ & $(0.074)$ & $(0.208)$ & \\
Intercept & 0.120 & -0.043 & -0.017 & 0.022 & -0.082 & 6.65 \\
& & $(0.032)$ & $(0.031)$ & $(0.040)$ & $(0.112)$ & \\
F-value & 10.318 & 13.560 & 18.552 & 23.686 & 33.885 & \\
Pr(F) & $(0.586)$ & $(0.363)$ & $(0.359)$ & $(0.455)$ & $(1.281)$ & \\
$R^{2}$ & & & & & & \\
\hline
\end{tabular}

Note: $T=31$. Equations were estimated by applying SUR to the quintile group shares 1 to 4 and solving for the 5 th equation coefficients from the adding up constraints (see footnote 5). Standard errors were obtained from adding-up constraint and the singularity of the full covariance matrix (Jäntti; 1994). The joint test is the F-test statistic for the joint hypothesis that the coefficient for a variable is zero in all equations. 


\begin{tabular}{|c|c|c|c|c|}
\hline \multirow[t]{4}{*}{ Variable } & \multicolumn{4}{|c|}{ Test statistics } \\
\hline & & & & \\
\hline & \multicolumn{4}{|c|}{ Maximal lag length } \\
\hline & 0 & 1 & 0 & 1 \\
\hline Singh-Maddala $a$ & 0.929 & 0.558 & 0.409 & 0.253 \\
\hline (corrected for heteroskedasticity) & 0.608 & 0.378 & 0.334 & 0.217 \\
\hline Singh-Maddala $q$ & 0.801 & 0.571 & 0.108 & 0.086 \\
\hline (corrected for heteroskedasticity) & 0.803 & 0.489 & 0.273 & 0.177 \\
\hline Overall unemployment rate & 2.454 & 1.281 & 0.254 & 0.139 \\
\hline real GDP growth & 0.178 & 0.146 & 0.069 & 0.057 \\
\hline Real interest rate & 0.742 & 0.418 & 0.498 & 0.283 \\
\hline Inflation rate & 0.574 & 0.329 & 0.477 & 0.274 \\
\hline Gini coefficient & 1.617 & 0.878 & 0.640 & 0.350 \\
\hline
\end{tabular}

Note: $\mathrm{T}=31$. Asymptotic critical values for the test statistics are $0.347(p=0.10)$ and $0.463(p=$ $0.05)$ in the level and $0.119(p=0.10)$ and $0.146(p=0.05)$ in the trend stationary case. See Kwiatkowski et al. (1992) for details. 
Table 4 The effect of macroeconomic variables on parameters of Singh-Maddala income distribution

\begin{tabular}{|c|c|c|c|c|}
\hline \multirow[t]{2}{*}{ Regressor } & \multirow[t]{2}{*}{ Parameter } & \multicolumn{3}{|c|}{ Model } \\
\hline & & $\bar{A}$ & $\bar{B}$ & $\overline{\mathrm{C}}$ \\
\hline \multirow[t]{6}{*}{ Unemployment rate (overall) } & $\bar{a}$ & -0.024 & -0.024 & -0.016 \\
\hline & & $(0.005)$ & $(0.005)$ & $(0.011)$ \\
\hline & $q$ & -0.068 & -0.063 & 0.045 \\
\hline & & $(0.016)$ & $(0.015)$ & $(0.022)$ \\
\hline & Joint F-test & 19.0 & 18.8 & 32.7 \\
\hline & $\operatorname{Prob}(\mathrm{F})$ & 0.00 & 0.00 & 0.00 \\
\hline \multirow[t]{6}{*}{ Inflation rate } & $a$ & -0.017 & -0.018 & -0.020 \\
\hline & & $(0.008)$ & $(0.009)$ & $(0.010)$ \\
\hline & $q$ & 0.000 & 0.030 & 0.001 \\
\hline & & $(0.025)$ & $(0.027)$ & $(0.020)$ \\
\hline & Joint F-test & 2.2 & 2.1 & 2.0 \\
\hline & $\operatorname{Prob}(\mathrm{F})$ & 0.12 & 0.13 & 0.14 \\
\hline \multirow[t]{6}{*}{ Real interest rate } & $a$ & & 0.000 & -0.010 \\
\hline & & & $(0.004)$ & $(0.013)$ \\
\hline & $q$ & & 0.024 & -0.114 \\
\hline & & & $(0.011)$ & $(0.026)$ \\
\hline & Joint F-test & & 2.1 & 4.3 \\
\hline & $\operatorname{Prob}(\mathrm{F})$ & & 0.12 & 0.02 \\
\hline \multirow[t]{6}{*}{ Real GDP growth rate } & $a$ & & & -0.015 \\
\hline & & & & $(0.018)$ \\
\hline & $q$ & & & -0.201 \\
\hline & & & & $(0.036)$ \\
\hline & Joint F-test & & & 14.6 \\
\hline & $\operatorname{Prob}(\mathrm{F})$ & & & 0.00 \\
\hline Log likelihood & & -95.6 & -93.2 & -80.7 \\
\hline
\end{tabular}

Note: $T=31$. Standard errors in parentheses. The F-test statistic that the coefficients are zero along with the $p$ value shown below the coefficient of the covariate in both equations. See Section I for estimation details. 


\section{IZA Discussion Papers}

\author{
No. Author(s) \\ 290 \\ D. A. Cobb-Clark \\ M. D. Connolly \\ C. Worswick
}

291

R. T. Riphahn

292

E. Wasmer

293

294

D. Cobb-Clark

T. F. Crossley

295

F. Duffy

P. P. Walsh

296

H. S. Nielsen

M. Rosholm

N. Smith

L. Husted

297

J. C. van Ours

J. Veenman

298

P. Telhado Pereira

P. Silva Martins

299
G. Brunello
C. Lucifora
R. Winter-Ebmer

300
A. Stutzer
R. Lalive

301

J. R. Frick

G. G. Wagner

Title

Area

Date

The Job Search and Education Investments of

1

04/01 Immigrant Families

Cohort Effects in the Educational Attainment of Second Generation Immigrants in Germany: An Analysis of Census Data

Between-group Competition in the Labor Market and the Rising Returns to Skill: US and France 1964-2000

Gender, Comparative Advantage and Labor

Market Activity in Immigrant Families

Estimating the Effect of Unemployment Insurance Compensation on the Labor Market Histories of Displaced Workers

Individual Pay and Outside Options:

Intergenerational Transmissions and the Schoolto-Work Transition of $2^{\text {nd }}$ Generation Immigrants

$05 / 01$

The Educational Attainment of Second

05/01

Generation Immigrants in The Netherlands

1

5

06/01

Returns to Education and Wage Equations

5

06/01

Students

5

06/01

Searching and Subjective Well-Being

Economic and Social Perspectives of Immigrant

1

06/01 

H. Bonin
G. Abío
E. Berenguer
J. Gil
C. Patxot

307

G. A. Pfann 

A. Frederiksen
E. K. Graversen
N. Smith

Germany: The Impact on Productivity and Wages 

Quality
A. Ibourk
B. Maillard
S. Perelman
H. R. Sneessens

The Matching Efficiency of Regional Labour

Markets: A Stochastic Production Frontier

Estimation, France 1990-1995 

ment Compensation System is More Prone to Labor Market Shocks? 


$$
\text { S. J. Trejo }
$$

